\title{
Building Professional Competences of English Language Teachers
}

\author{
Lyudmila Karpova*, Elena Grigorieva, Elena Ladonina, Olga Popova, and Anna Shchekoldina
}

Volgograd State University, Foreign Language Communication Department, Volgograd, Russia

\begin{abstract}
This article is devoted to the problem of building professional competences for the teaching profession. The paper highlights four main groups of professional competences: cultural and linguistic competences, linguistic and didactic competences, social and educational competences, professional and educational competences. It presents a brief summary of key skills a person should possess to be a competent foreign language teacher. Foreign language teachers should act as professional inheritors, critics and interpreters of knowledge and culture when teaching students. They also have to be able to communicate clearly in the language of instruction, using correct grammar, in various contexts related to teaching. Moreover a foreign language teacher should adapt his or her teaching to the needs of students with various disabilities, integrate ICT in teaching activities, cooperate with school staff, parents and students in pursuing the educational objectives, collaborate with the teaching team in developing programs and projects when teaching students. The article attempts to identify learning situations that are appropriate to the students concerned and the subject content with view to developing the competences targeted. The study can help in designing and modelling the educational process within the frameworks of the competence approach.
\end{abstract}

\section{Introduction}

The State Educational Standard of Higher Professional Education requires that in teaching a foreign language, professional specificity should be taken into account i.e. the aim is to handle tasks of graduates' future professional activity.

Professionally oriented teaching is teaching based on considering students' needs in the foreign language learning process and dictated by peculiarities of their future profession or speciality. A modern professionally oriented approach to teaching a foreign language assumes forming students' foreign language communicative ability, in particular professional, business, scientific environments and situations, while taking into consideration professional thinking peculiarities and arrangement of motivational, stimulating and research oriented activity.

The system of foreign language knowledge, abilities and skills acquired by students is defined by a complex of competences, which are formed in the process of their foreign language learning activity. Thus, the student himself and building his professional competence (a complex of competences) are in the centre of professionally oriented teaching.

The core constituent of the foreign language communicative competence is defined by a set of professional competences, which the graduate of this specialization must possess after graduating a higher education institution.
The ability to communicate in a foreign language professional environment takes on a special value when teaching linguists, future foreign language teachers. The competence approach to the professional education of future teachers allows assigning the spectrum of abilities, which the graduate of this specialization must possess. The professional foreign language communicative competence is a multifaceted concept interpreted as a complex set of competences, which provide graduates' all-round training for their future educational work [1].

Professionally oriented linguistic education of foreign language teachers is reflected in teaching all linguistic aspects and acquiring all types of speech activity, especially by senior students whose professional constituent of their foreign language learning becomes first-priority [2].

\section{English language teachers' professional competences}

In accordance with the competence approach to the professional education of foreign language teachers, we regard the professional foreign language competence as the fundamental one taking into account its multipleaspect content [3]. Among its constituents, the emphasis is put on building the following core ones: cultural and linguistic competences, linguistic and didactic competences, social and educational competences, professional and educational competences. 


\subsection{Cultural and linguistic competences}

Cultural and linguistic competences include the following abilities: to be an inheritor of linguistic knowledge and culture; to communicate clearly in the language of instruction, using correct grammar, in a spoken or written form, in various contexts related to teaching a foreign language.

A foreign language teacher as an inheritor of linguistic knowledge and culture has to be able to set a priority in the process of learning basic linguistic categories and postulates so that students can comprehend them well and learn effectively. A critical approach to the content of the subject under study that gives an opportunity to the teacher to evaluate the significance of this or that concept for the educational context is also very important. As all curricula are the products of cultural heritage, which are used in a certain historical environment; academic subjects are submitted to the dynamics of changes reflecting the reality of modern life. Therefore, competent teachers should not restrain their role by simple transference of the subject content; they should realize the conditions of occurrence and the confines of existence of concepts taught by them. That is the skill to be critical of the subject content and curriculum.

The sociocultural approach to the learning process facilitates forming a foreign culture comprehension and establishing its links with home culture. Future teachers have to be able to turn the classroom into a cultural base open to many views within the frameworks of a common discussion space, and also, to form the skill in analysing and evaluating a foreign language learning content in a particular group of students [4].

The specificity of the professional activity of foreign language teachers allows embracing different layers of cultural heritage of the target language countries paying special attention to the aspects actual amid children and the youth. Such themes as Educational and Health Issues, State Political Systems, Juvenile Delinquency are essential in each culture. Accordingly, their inclusion into the curriculum of future foreign language teachers within the frameworks of a practical language course is reasonable [5]. When working with students at Volgograd State University, in the educational course "Foreign language teaching methods and theory", we suggest, for instance, that they should study texts about basic health care systems, discuss their advantages and disadvantages and draw conclusions defending their views: Name advantages and disadvantages of every health care model. Work in groups to prove that this or that model is the best one. While studying Health Issues students discuss the most important problems of the juvenile age: prevention and fight against harmful habits (smoking, alcohol, drugs), necessity of leading a healthy way of life (balanced feeding, physical exercise):

- Read about tobacco, alcohol and substance abuse. Speak on the most urgent health problems using the general information and giving some more details from additional texts.

- Speak on the following: the importance of health education at school; the problem of tobacco use among young people.
- Read "Living a Healthy Way of Life is No Mystery" and say whether you agree or disagree with the author's point of view. Discuss it with your partner.

- Generalize all the ideas of a healthy lifestyle and make a short report on the topic.

While working with students of this educational course, we highlight the skill to communicate clearly in the language of instruction, use correct grammar (in a spoken or written form) in various contexts related to teaching a foreign language that lies, first of all, in the correct choice of language means while communicating with students, their parents and peers. When working with students, it is necessary to remember that teachers, whose mission is to teach, should keep the distance setting the pattern of official communication. Professional communication in a foreign language requires that teachers-linguists should possess the ability to speak with each other at a rather high scientific and cultural level. They should also possess both extensive theoretical written language knowledge (the observance of grammar rules and laws of stylistics and their compliance with the situation of communication) and the ability to apply this knowledge demonstrating some patterns of written texts to their students.

This competence also means the skill to logically explain and effectively defend one's point of view during a discussion in the classroom showing respect to opponents. It is closely connected with the ability to constructively use well-chosen lexis and syntax, correct students' mistakes in a spoken or written form, and with a constant desire to upgrade spoken and written language abilities [6].

Developing the skills to give precise and correct instruction and explanation in the foreign language in professionally oriented situations, future teachers adopt appropriate linguistic means (core lexis, grammar constructions and speech patterns). For example, they are given two concepts - Teacher Training u Teacher Development - to become familiar with and then to discuss [7]. Each concept corresponds to a number of lexical units, the use of which is illustrated in the text then practiced in pre-communicative and communicative activities:

- The words and expressions below are from the article. Without reading the article again, decide whether they relate to Teacher Development or Teacher Training.

- Practise saying the words and expressions and then compare your answers with a partner. Read the article again and check your answers.

- Complete the chart below with words from the article, or words based on them.

- Now write sentences about yourself with at least one of the words in each row. Then discuss your sentences with your partner.

- Talk about one or both of the points with a partner or partners: 1. Is teacher development more useful than teacher training? 2. What opportunities for teacher training or teacher development are open to you?

The ability to instruct in a foreign language in the classroom is one the most important skills in a complex of teachers' core foreign language competences, so the 
practical course of a foreign language should include such a section as Classroom Instruction. For example, the following tasks are supposed to teach students to introduce the task on True/ False statements:

- A teacher must introduce a true/false activity with the instructions below. Read them, and then fill in the blanks (some key words are missing).

- Now introduce the same activity to a partner as if you were speaking to a class. Use your own words or these above.

- Home task: prepare a true/false activity on one of the previous topics for the next class.

\subsection{Linguistic and didactic competences}

Linguistic and didactic competences include the following skills: to develop learning situations for achieving goals and objectives of a particular group of students; to create new situations for achieving the goals and objectives of a particular group of students; to assess the level of development and achievements of students in accordance with the specific content of education and the development of relevant competences; to plan, organize and monitor the activities of students in the classroom in such a way as to contribute to the successful development of their individual and collective learning skills [8].

The selection of content should be based on the latest achievements of didactic and pedagogical studies and should take into account the learning objectives for a particular profile program. It is necessary to plan the process of learning and evaluating results, taking into consideration the logical sequence of mastering the content elements. There should be a clear understanding of the set of skills that are to be developed during a certain period of training on the base of specific subject content required for the building of relevant competences. The profile subject content sets parameters for the development of learning situations. The process of their creation assumes a deep understanding of the meaning of a particular situation, its limits and its relationships with other fields of knowledge, in particular, with the social and cultural sphere.

When selecting situations of communication, we pay special attention to the social characteristics of different groups of students. Future teachers should be able to apply a variety of didactic approaches in teaching a foreign language, taking into account the specific level of development of the communicative competences of students. They should anticipate and overcome the emerging difficulties and obstacles and create new situations of communication in accordance with emerging needs.

Future teachers should be able to create conditions in which students can solve problems and create projects using their cognitive and emotional abilities and taking into account social characteristics. The cognitive level assumes situations of "disequilibrium" which contain certain difficulties and obstacles for immediate solution and require certain efforts and a number of actions aimed at achieving the result. This facilitates the reproduction of previously acquired knowledge and the integrated use of skills. The existence of the problem makes the situation universal, allows it to be formulated, classified and correlated with a certain area of knowledge, which in turn facilitates the selection, interpretation and understanding of information coming from various sources, provides quick and relevant feedback in the learning process and supports teamwork.

Problem situations create excellent conditions for motivating the learning process. The situation, which at first seems to make no sense, quickly takes new forms in the process of analysis, detailed consideration and joint discussion. Going into details of the problem situation, the teacher, together with the students, determines its connections with other everyday situations in which the same concepts appear, revealing students' ability to solve the problem, showing them the available resources and stimulating the memory for reproduction of similar actions, taken earlier. This in turn leads to application of methods and strategies, which are well-known to students and give them a sense of control over their own knowledge.

Planning necessarily includes evaluation mechanisms. Teachers must develop characteristics of situations and criteria for assessing students' knowledge and skills acquired within a specific training cycle. Teachers are required to have the ability to collect and accumulate information about the strengths and weaknesses of their students, to reassess and adapt pedagogical activities in accordance with this knowledge, to develop and use tools and techniques for assessing the development level of competencies of a particular student. It is essential to develop selfmanagement skills in the learning process, using different methods such as checklists, tabulating corrected mistakes, exercise keys, joint checking and correction of mistakes, the selection of examples and diagrams, interactive consultations with the teacher, etc.

Planning, organizing and monitoring students' activities are to be complied effectively and systematically, taking into account the instruction program of the group. Teachers should clearly and intelligibly explain to students their academic requirements, involve them in various types of work (both individual and group), develop strategies to prevent disciplinary problems in the classroom and solve these problems successfully in the event they arise, create a favourable working environment in the classroom. Effective classroom work requires careful planning and implementing the plans from the very beginning of the training course, which gives teachers the opportunity to foresee and prevent possible procedural problems that lead to students' attention decline, and also, to the decline in students' achievements.

The ability of teachers to involve students in active classroom work assumes the ability of students to listen attentively and to exchange opinions, which contributes to the gradual development of students' skills to formulate common goals and find common methods [4].

The linguistic and didactic component of the profile foreign language competence is realized in the content of 
the curriculum for future foreign language teachers: a set of situations directly reflects the aspects of the professional pedagogical activity of foreign language teachers. We have selected the following situations of professional communication:

- Discussing the sphere of communication - types and components of communication.

- Talking about how to teach and learn foreign languages.

- Discussing course books, their description and evaluation.

- Discussing various learning situations at the English lessons.

- Discussing work relationships and feelings.

- Talking about teacher training and teacher development.

- Talking about teacher and learner behaviour.

- Talking about personal development - plans, intentions, etc.

- Discussing the job of an English language teacher, work peculiarities and conditions.

- Talking about how to organize the teacher's time duties and activities.

- Describing a teacher's character - character traits which can help you become a successful teacher.

- Troubleshooting - talking about classroom discipline and management.

- Discussing gender problems - classroom behaviour of boys and girls.

- Discussing free time activities.

\subsection{Social and educational competences}

Social and educational competences include building the following skills: to adapt teaching activities to the needs of students with different individual characteristics, disabilities and limited opportunities; to integrate information and communication technologies in teaching activities and in the process of professional selfimprovement; to cooperate with the school team, parents and students in achieving educational goals; to cooperate with colleagues in order to succeed in developing competencies that are part of the instruction program for a particular group of students, and to assess these competences development level [9].

In the modern society, future teachers should have the skill to adapt teaching activities to the needs of students with different individual characteristics, disabilities and limited opportunities. They should be able to:

- promote the socialization and integration of students with disabilities (mental or physical disabilities, social disadaptation) into the educational process,

- communicate with social workers and parents of such students in order to obtain biographical information necessary for ensuring a successful educational process;

- set educational tasks, ask questions and offer roles that help to successfully master the training material and realize the abilities of students;

- develop individual training and evaluation plans using new educational technologies.
Social and educational competences involve the skills of integrating ICT in teaching activities and the process of professional development. In the technological progress era, it is impossible to do without the ability to use the computer and network potential for achieving the set goals and developing the relevant competences in the educational process, to use multimedia resources for searching, interpreting and exchanging information, performing problem-oriented tasks and communication. A teacher has to be able to use ICT to create links promoting the effective exchange of information and professional development in the relevant scientific and practical sphere. A teacher should develop students' skills in working with ICT, teach them how to use ICT, extract and evaluate the information found in the Internet [4].

On such famous sites as www.teachingenglish.ork.uk you can find a lot of interesting information for students and teachers, e.g. lesson plans, prompts, problems of teaching different age groups, publication of articles on the methodology of teaching English, recorded seminars, webinars, materials of scientific and practical conferences, opportunities to improve the professional level online, etc. The wireless access to the Internet within the University provides an opportunity for classes to use materials from such sites as well as give the assignments for independent work. ICT provides increasing the level of professional linguistic and educational training of future foreign language teachers.

The skills to cooperate with the school staff, parents, partners and students in pursuing the educational objectives are also of paramount importance among the social and educational competences of the future teacher. They include the following: identifying areas for developing and implementing education-related projects at the local level in collaboration with other school staff representatives; informing and involving parents in activities related to the school problems; coordinating professional activities with the work of various organizations such as the school partners; giving assistance to students engaged in school administrative structures or participating in various school projects and events.

Another important skill among social and educational competences is cooperation with the teaching team in developing competences that are part of the training program for a particular group of students and evaluating the level of building these competences. A teacher has to be able to recognize situations when the cooperation with the teaching team is necessary to pursue a certain objective and evaluate the students' progress, or when it requires a joint increase/decrease in the level of competences tested at the end of the course. A teacher has to be able to develop and implement a project that meets the objectives of the school staff. It is necessary to learn how to cooperate openly with the teaching team working with one group of students. Teamwork implies the ability to respect the teaching team opinion, contribute to the overall activity promoting the effective achievement of the set goals. 


\subsection{Professional and educational competences}

Professional and educational competences involve the skills in organizing the professional development individually and with the teaching team and demonstrating ethical and responsive professional behaviour.

The skill in self-development and self-improvement, the ability to use all the opportunities and sources to improve the skills may be considered the most important professional competences of future teachers. This also involves the skills to analyse their own experience and the teaching team's achievements, to share their ideas, to work out joint programs and projects that are consistent with the educational objectives assigned to a particular institution [10].

Teacher's professional competences must include the ability to demonstrate ethical and responsive professional behaviour. The ethical competence involves the ability to follow moral principles, describe, discuss and defend the moral stance, monitor the compliance with the rules of constructive discussion. The ethical standards of behaviour require the teacher should have a democratic management style, provide students with appropriate attention and support, justify decisions in the learning process, maintain confidentiality in special cases related to educational activity, avoid any form of discrimination against students, demonstrate justice in application of administrative law in resolving various conflicts and problems.

\section{Conclusion}

The higher professional education mission is to develop specific professional skills required in the future activities of the university graduates. A professionally oriented approach to learning a foreign language involves building students' ability in foreign language communication within specific professional, business, academic situations taking into account the characteristics of professional thinking and application of knowledge. The professional component of the foreign language communicative competence is composed of a set of professional competences that a graduate must have. Such professional competences as cultural and linguistic competences, linguistic and didactic competences, social and educational competences, professional and educational competences are particularly relevant for training future foreign language teachers. Thus, all these components comprise the foreign language teachers' professional competence and should be taken into consideration while planning and selecting the content for practical foreign language classes.

\section{References}

1. N.A. Gluzman, Fundamental science and technology - promising developments IX (North Charleston, 32, 2016)
2. A.V. Schekoldina, Current problems of linguistics and didactics: concepts and perspectives, International Scientific Conference (Volgograd, VolSU, 2011)

3. O. Redkin, O. Bernikova, 3rd International Multidisciplinary Scientific Conference on Social Sciences and Arts: Psychology and Psychiatry, Sociology and Healthcare, Education Conference Proceedings I, 757 (2016)

4. C. Gauthier, M.A. Martinet, D. Raymond, Teacher Training. Orientations. Professional Competences, (Quebeck, 2001)

5. L.I. Karpova, Language and speech communication in semiotic, functional and discursive aspects, International Scientific Conference (Volgograd, VolSU, 2012)

6. E. Golubovskaya, N. Pletneva, 3rd International Multidisciplinary Scientific Conference on Social Sciences and Arts: Psychology and Psychiatry, Sociology and Healthcare, Education Conference Proceedings I, 701 (2016)

7. M. Spratt, English for the Teacher: A Language Development Course (Cambridge University Press, 13th Printing, 2005)

8. E. Pankratova, 3rd International Multidisciplinary Scientific Conference on Social Sciences and Arts: Psychology and Psychiatry, Sociology and Healthcare, Education Conference Proceedings I, 641 (2016)

9. M.I. Lorsanova, Fundamental science and technology - promising developments IX (North Charleston, 2016)

10. E.A. Nalivaiko, Fundamental science and technology - promising developments IX (North Charleston, 2016) 